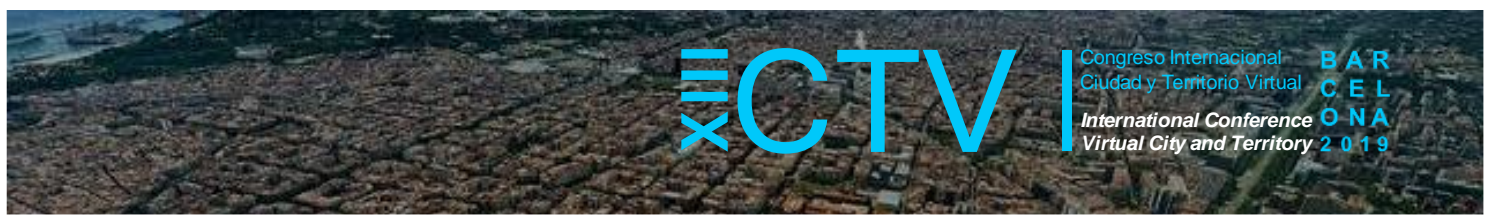

\title{
ARQUITECTURAS DEL BAÑO FRENTE A LA SUBIDA DE LA COTA CERO
}

\author{
Gilabert Campos, Miguel Ángel ${ }^{1}$; Castellano Pulido, Francisco Javier ${ }^{2}$ y García Píriz, Tomás ${ }^{3}$
}

Remisión inicial: 2019-05-30; Remisión definitiva: 2019-09-19; Publicación: 2019-12-21

Citación: Gilabert Campos, M. A. et al. (2019). Arquitecturas del baño frente a la subida de la cota cero. En XIII CTV 2019 Proceedings: XIII International Conference on Virtual City and Territory: "Challenges and paradigms of the contemporary city": UPC, Barcelona, October 2-4, 2019. Barcelona: CPSV, 2019, p. 8482. E-ISSN 2604-6512. DOI http://dx.doi.org/10.5821/ctv.8482

\section{Resumen}

La gran transformación de los paisajes litorales previsible en las próximas décadas, intensificada por los efectos del llamado cambio climático, constituye un ámbito de estudio de creciente interés por parte de la arquitectura. Más allá de los graves impactos que pueden producirse en el medio urbanizado, este fenómeno establece una oportunidad para repensar la relación de las ciudades litorales con su ribera marítima. Esta investigación se centra en la capacidad de respuesta de la arquitectura ante la transformación del medio litoral como consecuencia de la subida del nivel del mar a partir de una tipología concreta: los espacios públicos asociados al baño (arquitecturas, infraestructuras o instalaciones destinadas al ocio de bañistas). Para ello, se describen y catalogan las principales estrategias que inciden sobre esta problemática a fin de poder establecer, desde la globalidad, estrategias de actuación para casos particulares.

Este estudio se estructura a través de una secuencia metodológica basada en la búsqueda, recopilación y análisis de documentación e información sobre intervenciones de espacios públicos vinculados al baño en frentes marítimos. Cada ejemplo es estudiado, catalogado y valorado mediante la consideración de una serie de parámetros que influyen en la particular relación entre el medio urbano y las zonas inundables. De este modo, puede elaborarse una tabla conceptual que identifica y organiza distintos proyectos arquitectónicos afectados por la subida del nivel del mar a través de la parametrización de conceptos aplicados a su diseño. Los resultados extraídos definen estrategias extrapolables que pueden ayudar a la reinvención del frente marítimo ante a los nuevos paradigmas costeros que se prevén por el cambio climático y la consiguiente subida del nivel del mar.

\begin{abstract}
The great transformation of the coastal landscapes foreseeable in the coming decades, intensified by the effects of the so-called climate change, constitutes a field of study of growing interest for architecture. Beyond the serious impacts that may occur in the urbanized environment, this phenomenon offers an opportunity to rethink the relationship of coastal cities with their seafronts. This research focuses on the capacity of architecture to respond to the transformation of the coastal environment as a result of the rise in sea level for a specific type of resource: public spaces associated with seaside recreation (architectures, infrastructure or facilities for leisure bathers). The main strategies that influence this problem are described and catalogued in order to establish, from a global perspective, action strategies for particular cases.

This study is structured through a methodological sequence based on the search, collection and analysis of documentation and information on interventions in public spaces linked to seaside leisure. Each example is studied, redrawn and valued considering a series of parameters that affect the relationship between the urban environment and areas at risk of flooding. In this way, a conceptual framework can be developed that identifies and organizes different architectural projects affected by sea level rise through the parameterization of concepts applied to their design. The results extracted define extrapolated strategies that can help to redesign the seafront in the face of the new coastal paradigms that are predicted by climate change and the consequent rise in sea level.
\end{abstract}

Palabras Clave: arquitecturas del baño; espacio público; frente marítimo; nivel del mar.

Key words: architecture for bathing; public space; seafront; sea level.

\footnotetext{
${ }^{1}$ Arquitecto, M.Sc., Universidad de Málaga, https://orcid.org/0000-0001-8386-9737; ${ }^{2}$ Doctor Arquitecto, Departamento de Arte y Arquitectura, Universidad de Málaga, https://orcid.org/0000-0002-9287-1983; 3 Doctor Arquitecto, Departamento de Expresión Gráfica Arquitectónica y en la Ingeniería, Universidad de Granada, https://orcid.org/00000003-3405-6806. * Correo de contacto: mgilabertcampos@gmail.com
} 


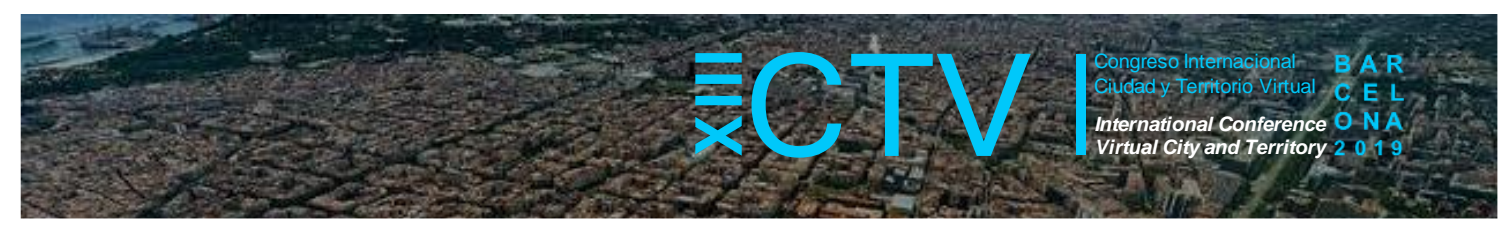

\section{Cambio climático y subida del nivel del mar: estado de la cuestión}

El último informe del IPCC (Intergovernmental Panel on Climate Change) emitido en 2014 introdujo nuevos paradigmas en referencia al cambio climático, configurándose como un documento clave en las futuras líneas de actuación respecto al calentamiento global.

Según este informe, la subida media del nivel del mar ha aumentado desde mediados del siglo XIX a un ritmo superior a la media de los dos últimos milenios. Se ha podido constatar una mayor aceleración de este aumento durante los primeros diez años del siglo $\mathrm{XX}$, situándose dicha subida media en $0,19 \mathrm{~m}$ (IPCC, 2014). Sobre las causas del cambio climático, el IPCC sostiene que es muy probable que más de la mitad del aumento de la temperatura media global acaecida en los últimos 50 años se debe a causas derivadas del efecto invernadero y otros forzamientos antropógenos (IPCC, 2014).

Las proyecciones indican que la tendencia actual se mantendrá y aumentará en las siguientes décadas. La elevación del nivel del mar continuará durante el siglo XXI y crecerá aún más de lo que se ha podido corroborar hasta ahora. De los distintos escenarios que se manejan, las situaciones más pesimistas apuntan a una subida del nivel del mar que podría llegar a los 0,82 $\mathrm{m}$ en el período comprendido entre 2081-2100.

A la espera de que el IPCC emita su sexto informe, previsto a finales de septiembre de 2019, otras instituciones continúan aportando datos que revelan nuevos escenarios anteriormente no contemplados por este organismo. Aun no ofreciéndose datos definitorios sobre el aumento previsto de la cota del nivel del mar, todas las predicciones coinciden en que dicho aumento será una realidad (Hinkel et al. 2018, Strauss. 2015, Bamber el al. 2009).

Por otra parte, existen pruebas históricas que muestran que la tierra ha sufrido periodos de grandes oscilaciones en su temperatura media (Castellano, García, 2011). En la capa terrestre se aprecian evidencias que revelan sucesivos períodos de enfriamiento y calentamiento durante los últimos 8000 años, lo que ha contribuido a una variación importante del nivel del mar durante distintas épocas. Según el Grupo de Dinámica de Flujos ambientales de la Universidad de Granada el siguiente pico de calentamiento estaría próximo a producirse en torno al año 2200-2300.

Según datos del Banco Mundial, el $70 \%$ de la población vive en asentamientos costeros sometidos a la amenaza de la subida del nivel del mar (BIRF, 2010). El crecimiento de las poblaciones de las zonas limítrofes con la costa es mucho mayor respecto al de las zonas interiores. Esto ha producido un progresivo interés por parte del sector de la arquitectura en el estudio de la ciudad en su interferencia con el mar, sus problemas y oportunidades para generar estrategias de futuro.

En la actualidad, muchas de las construcciones realizadas a lo largo de los frentes marítimos no están diseñadas para soportar eventos de subida del agua y los efectos cambiantes del clima (Schiermeier, 2011). Las infraestructuras se muestran obsoletas o son insuficientes. Las actuaciones en frentes marítimos suelen verse limitadas a acciones de protección que no atienden al paso del tiempo ni a las dinámicas de transformación del paisaje. 


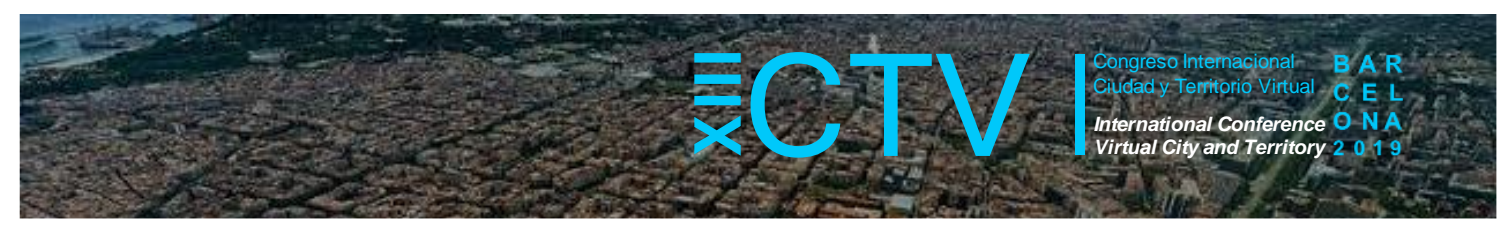

Además de los peligros derivados de la insuficiencia infraestructural, las propuestas que no atienden a la variable temporal en su concepción suelen suponer un importante aumento de los costes al cabo del tiempo. El gasto de la recuperación es nueve veces mayor que el que se hace en la prevención (Szoenyi, 2018), por lo que urge la creación de soluciones innovadoras que hagan frente a las posibles repercusiones del aumento del nivel del mar.

Los expertos del Foro Económico Mundial advierten que las ciudades en situación de riesgo deben adaptarse intentando evitar la inundación y/o aprendiendo a vivir con la subida del mar. Se plantean tres estrategias adaptativas principales: la construcción de estructuras duras (normalmente de contención), las defensas blandas (basadas en el trabajo con la naturaleza) y, por último, la estrategia que trabaja con las personas (trasladándolas a terrenos más seguros 0 invirtiendo capital en generar comunidades más resilientes) (FEM 2019).

Mediante la adaptación a los cambios previstos del sistema climático se pretende dar respuestas a un problema complejo y de múltiples variables, por lo que es necesaria una visión holística que implique múltiples voces cualificadas. El presente estudio se centra en el análisis de arquitecturas que han aplicado estrategias adaptativas frente a las variaciones del nivel del mar. De las arquitecturas analizadas se presta especial atención a aquellas que trabajan con la creación de defensas blandas, aunque en muchos casos se complementan con la creación de frentes duros, evitando el desplazamiento de personas a terrenos alejados de la costa.

Esta investigación se centra en la capacidad de respuesta de la arquitectura ante la transformación del medio litoral como consecuencia de la subida del nivel del mar a partir de una tipología concreta: los espacios públicos asociados al baño. Se trata de obras que no solo han sido proyectadas desde la contención de las aguas si no que negocian con ellas mediante estrategias que atienden a la adaptación de las dinámicas marinas. Se analizan, describen y catalogan arquitecturas históricas vinculadas al baño que inciden sobre esta problemática a fin de poder establecer, desde la globalidad, estrategias de actuación para casos particulares.

\section{Arquitecturas del baño: desde el siglo XIX hasta la actualidad}

La revolución médica del siglo XVIII y el consiguiente equilibrio entre cuerpo y mente es el hecho que vuelve a configurar al agua como un elemento revitalizador por primera vez desde la Edad Media. Los postulados románticos, influidos principalmente por Jean-Jacques Rousseau, rescatan los instintos primarios del retorno al mundo natural y la aparición de las abluciones con agua fría. Durante los siglos XVIII y XIX, en gran parte de Europa, se construyen edificios de baño vinculados al mar coincidiendo con la aparición de la talasoterapia (González Soutelo, 2008) que se basa en los cuidados derivados de las bondades del agua de mar y su entorno. El tiempo para el ocio y el culto al cuerpo y su cuidado comienza a extenderse entre las clases altas, aunque no se generalizarán al resto de la sociedad hasta bien entrado el siglo XX.

Paralelamente al caso europeo de los centros de talasoterapia, y relacionados directamente con las bondades del agua del mar y su entorno, en los países nórdicos surgen las casas de baños. Durante el siglo XIX, los baños fríos, spas y las saunas comienzan a proliferar bajo el nuevo paradigma que retomaba la importancia del agua, del cuidado de la salud y la natación, rescatando antiguas tradiciones vernáculas vikingas. 


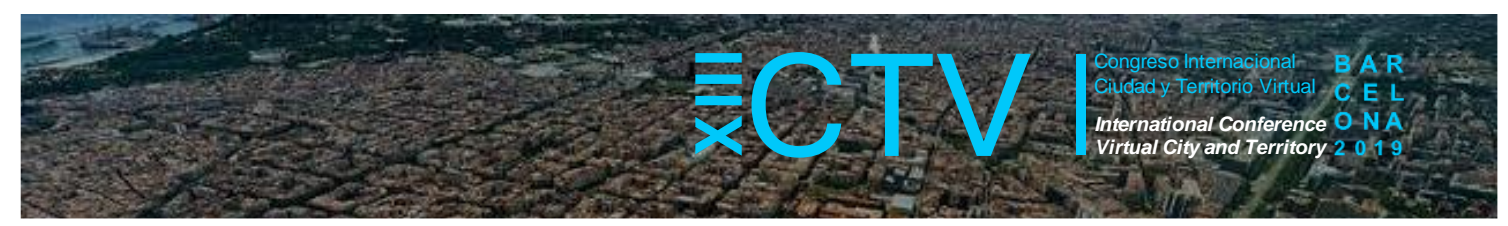

Las casas de baños públicas también proliferaron en EEUU durante el siglo XIX y principios del siglo XX. En Nueva York comenzaron a construirse edificios públicos para ayudar a mejorar el nivel de higiene de las clases sociales más pobres, ya que el agua corriente no era común en las zonas más desfavorecidas de la ciudad. En la Costa Oeste se desarrollaron una serie de casas de baño sobre muelles que tuvieron su apogeo entre las décadas de 1880 a 1920 (Masters, 2016). Eran edificios que contaban con baños disponibles durante todo el año.

Como sostiene González Soutelo, aunque las casas de baño tuvieron una gran repercusión social y se extendieron por toda Europa "diferentes factores como el despegue del turismo de masas, los conflictos internacionales y problemas sociales y económicos vividos durante el siglo XX, provocaron el progresivo declive y el abandono de estos espacios, hasta su posterior recuperación en la década de los 90" (González Soutelo, 2008, pág. 230).

Estos establecimientos basaban su funcionamiento en diversos modos de aprovechar las propiedades del agua de mar. Estructuralmente recordaban a los piers ingleses, generando un plano volado que se introducía desde la playa hacia el interior del mar. Una vez sobre el agua, aparecían distintos usos: baños calientes, bañeras, vestuarios y baños flotantes. Las casas de olas y los piers anticipan cuestiones relativas a la introducción de múltiples usos vinculados a la línea costera e implantan, por primera vez desde las termas construidas sobre palafitos del imperio romano (Yegül, 1991), una tipología arquitectónica capaz de negociar las variaciones del nivel del mar sin ser un elemento meramente defensivo. De esta forma, muelles ingleses, casas de baños y saunas nórdicas serán los primeros ejemplos de arquitecturas vinculadas al baño que se adentran en el mar, elevándose sobre estructuras ligeras que sortean las mareas y en las que se apoya un plano que configura un nuevo suelo volado.

Una aportación novedosa dentro de las arquitecturas destinadas al baño son las bathing machines. Herederas de la tradición victoriana y sus estrictos modales, estas infraestructuras se presentaban en forma de carromatos dispuestos en la línea de costa en los que los bañistas se introducían vestidos, se cambiaban y eran conducidos al interior del mar, mediante la fuerza proporcionada por caballos o sirvientes, para sumergirse sin ser vistos en traje de baño. Las casetas se desplazaban por la arena, avanzando o retrocediendo según las mareas. La playa funcionaba como soporte para que la arquitectura se desplace rodando por ella, introduciendo un componente estratégico único de movilidad y adaptabilidad al mar que no tuvo difusión posterior.

En la playa de la concha de San Sebastián, en 1894, se construiría un palacio de madera sobre raíles que permitía que la familia real de Alfonso XIII pudiera ser trasladada desde la arena hacia el interior del mar, donde podían bañarse sin ser vistos por el pueblo (Martínez, 2008). El palacio se desplazaba sobre los raíles gracias a la propulsión por un motor de vapor.

A principios del siglo $\mathrm{XX}$, en el período de entre guerras, surge un cambio de mentalidad y costumbres respecto al cuerpo: aparece el concepto contemporáneo de vida al aire libre. En los años 30, la aglomeración, la falta de espacio y la sensación de ahogo en las ciudades, hace que las clases medias y trabajadoras comiencen a demandar una atmósfera sana lejos de las urbes y en contacto con las playas (Pardo, 2016). Este cambio de paradigma contribuirá a la desaparición progresiva de las casas de baño. 


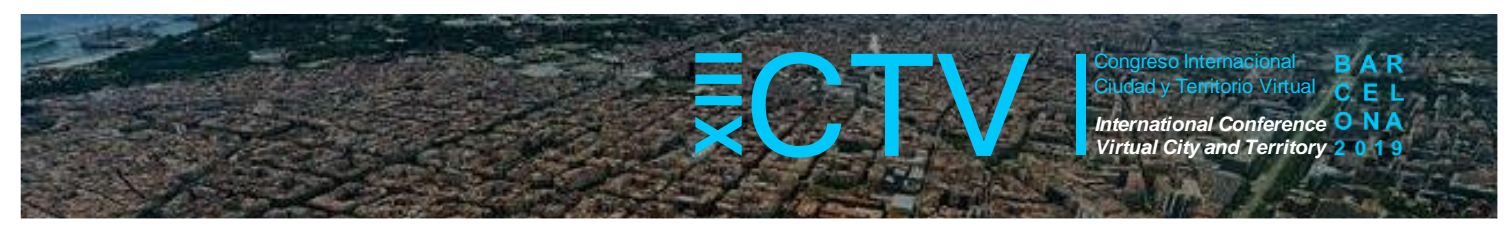

Dos hitos principales colaboran en la revolución en el tiempo libre: las vacaciones pagadas y la libertad del espacio vital de la segunda residencia. Estos aspectos hacen que el cuerpo participe de una liberación tanto física como espacial (Pardo, 2016). La exhibición del cuerpo dejará de considerarse algo impúdico, el bronceado dejará de asociarse a las clases bajas, entendiéndose como un signo de distinción social. Desde entonces, el baño en el mar se concibe como una actividad de ocio y esparcimiento vinculada a las vacaciones y la playa será el principal soporte arquitectónico del baño. Es el camino que conduce a los bañistas al agua.

En las localizaciones en que las corrientes marinas y el oleaje son fuertes, dificultando el nado en mar abierto, los bañistas han buscado de manera espontánea la protección de las rocas y las piscinas naturales que en ellas se forman. El amparo de las piedras proporciona aguas calmadas para el ocio y el juego. A partir de la segunda mitad del siglo XX, comienzan a proliferar arquitecturas integradas en el paisaje que se sirven de la orografía para insertarse en él causando el menor impacto posible. Diseños de mínima intervención en la naturaleza que buscan consolidar, introduciendo sistemas de contención duros, las preexistencias rocosas y posibilitar un baño controlado más allá de temporales y fuertes corrientes.

Estas arquitecturas son interesantes por su cuidadosa atención por el entorno en el que se desarrollan y por el diálogo que establecen con las variaciones del nivel del mar, adaptándose y asumiendo los cambios de cota producidos por el agua o permaneciendo inalterados a ellos a la vez que consolidan tradiciones relativas al baño a través del proyecto de arquitectura.

A lo largo del siglo XIX muchas ciudades costeras fueron ampliando y modernizando sus puertos. Estas operaciones desencadenaron una serie de transformaciones físicas en los entornos inmediatos a las infraestructuras portuarias. En los alrededores de los puertos se generaron nuevas operaciones urbanísticas, interiores y exteriores, entre las que destacan los paseos marítimos.

Como sostiene Juan Jesús Trapero (1986), los paseos marítimos poseen una doble dimensión: son los encargados de la defensa del litoral y se configuran como elemento clave en el urbanismo de las ciudades costeras al ser la fachada de la ciudad al mar. Como elementos defensivos, los paseos marítimos siguen múltiples estrategias y sus características formales varían según su localización.

Frente a los muros elevados y pétreos decimonónicos, en la actualidad encontramos ejemplos que eliminan resistencia a las aguas a través de operaciones que conducen al mar de manera tendida. A través del conocimiento de las características litorales y el estudio interdisciplinar, que involucra a expertos de distintas materias, se han proyectado nuevos elementos de contención, escalonados y suaves, que realizan la misma función de muros y diques pero que eliminan el componente amurallado de estos. De esta forma, se favorece la conexión entre ciudad y playa dotándolos de un papel urbano preponderante al tiempo que se ofrecen como elementos lúdicos de paseo y contemplación. Se podría hablar entonces de caminos hacia el baño, sendas de agua capaces de adaptarse a las variaciones del nivel del mar.

Desde la última década del siglo XX hasta la actualidad, se han desarrollado numerosas propuestas que inciden en la paulatina pérdida de carga de las actividades portuarias en las riberas de los mares y los ríos. 


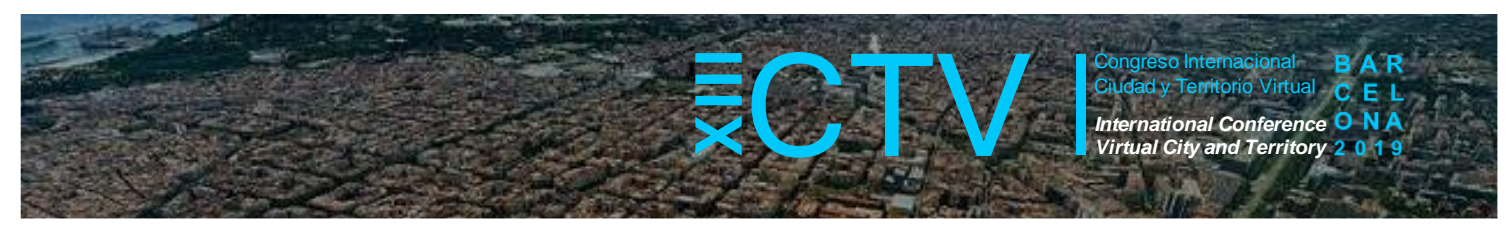

Ciudades europeas y americanas han proyectado o están estudiando la recuperación de los ríos como elementos lúdicos donde introducir dispositivos arquitectónicos vinculados al baño (casos como Berlín, París o Nueva York). Además, estas arquitecturas normalmente colaboran en la recuperación medioambiental de estos grandes ríos, por largo tiempo inaccesibles por su contaminación.

La progresiva desaparición de las actividades portuarias y las amplias superficies que ocupan aumenta la accesibilidad a los puertos convirtiéndolos en espacios de potencial y oportunidad. Especialmente interesante para este trabajo son las propuestas desarrolladas en los países nórdicos bañados por el mar del norte y el mar báltico. En Copenhague, por ejemplo, el agua y las experiencias relativas a ella se han constituido como un motor principal en la regeneración recreativa y urbanística de la ciudad. Desde las autoridades locales se ha contado con equipos experimentales de arquitectos y paisajistas para desarrollar propuestas integradoras que reinterpreten el espacio marítimo (Copenhague, 2010).

Un gran número de estas propuestas de regeneración pública introducen intervenciones que basan su estrategia proyectiva en la flotabilidad. Los elementos flotantes, herederos de la tradición holandesa de las casas sobre canales, poseen una serie de características propias y exclusivas. Además de encontrarse directamente en entornos naturales y poder disfrutar de los beneficios que estos puedan ofrecer, las arquitecturas flotantes permiten la adaptabilidad a los cambios derivados de los aumentos y descensos del nivel del mar, están preparados para poder ser reubicados en otros lugares gracias a sus propiedades móviles y, además, disponen de un acceso directo para servirse de energías renovables, ya que este tipo de energías son más fácilmente captables desde en mar abierto (Moon, 2017).

Desde la aparición de las casas de baño en el siglo XIX hasta las propuestas flotantes de la actualidad, la arquitectura del baño en los frentes marítimos ha funcionado como acuerdo entre la tierra y el mar. Es una tipología arquitectónica que históricamente ha vivido de la interacción con el agua, generando un particular diálogo con ella, y se configura como una de las primeras y más radicales formas evolutivas de adaptación a las variaciones del nivel del mar.

\section{Casos de estudio y estrategias de las arquitecturas del baño}

La metodología utilizada a lo largo de la investigación sobre la evolución de las arquitecturas vinculadas al baño se basa en la selección y clasificación de una serie de propuestas arquitectónicas de referencia, que abarcan desde el siglo XIX a la actualidad, procurando un alcance geográficamente significativo. Estos ejemplos se clasifican en la Tabla 1 con el fin de generar un atlas de casos de estudio de donde poder extraer claves y conclusiones relativas a su diseño y la particular relación que establecen en el contacto entre la tierra y el mar.

La mencionada tabla muestra una parte representativa de proyectos pertenecientes a una investigación mayor en curso. Los ejemplos presentados se clasifican cronológicamente por autoría, nombre de la intervención, fechas de proyecto y fechas ejecución de la obra y datos relativos a la localización (ciudad, país y mar o río con el que interactúan). Involucran a 15 países y 36 ciudades y, aun no pretendiendo ser una colección exhaustiva, intenta mostrar un amplio abanico de soluciones que respalden la investigación y sirvan como ejemplos de buena praxis para establecer nuevas formas de actuación ante la subida del nivel del mar. 


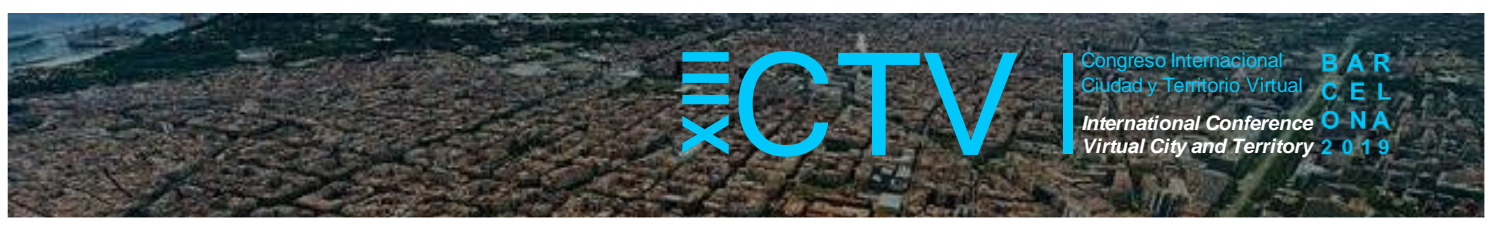

Tabla 1. Arquitecturas vinculadas al baño que interactúan con la subida del nivel del mar

\begin{tabular}{|c|c|c|c|c|c|c|}
\hline Autor & Obra & Proyecto & Ejecución & Ciudad & País & Mar \\
\hline John Löfmark & Borgholms kallbadhus & - & 1882 & Öland & Suecia & Norte-Báltico \\
\hline- & Dragør Søbad & - & 1890 & Copenhague & Dinamarca & Norte-Báltico \\
\hline- & Varbergs kallbadhus & 1866 & 1903 & Varberg & Suecia & Norte-Báltico \\
\hline- & Palsjobaden & - & 1909 & Helsingborg & Suecia & Norte-Báltico \\
\hline- & Liljeholmsbadet & - & 1930 & Estocolmo & Suecia & Río \\
\hline- & Helgoland Badeanstalt & - & 1933 & Copenhague & Dinamarca & Norte-Báltico \\
\hline Álvaro Siza & Piscina das Mares & 1961 & 1967 & Matosinhos & Portugal & Atlántico \\
\hline Fernando Menis & Piscinas Naturales & - & 1993 & Tenerife & España & Atlántico \\
\hline- & Fisketorvet Harbour Bath & - & 2002 & Copenhague & Dinamarca & Norte-Báltico \\
\hline Rintala Eggertsson & Floating Sauna & - & 2003 & Rosendal & Noruega & Lago \\
\hline Fernando Menis & Piscinas río Spree & 2003 & 2004 & Berlín & Alemania & Río Spree \\
\hline $\mathrm{BIG}+\mathrm{JDS}$ & Cop City Council & 2002 & 2005 & Copenhague & Dinamarca & Norte-Báltico \\
\hline Nikola Bašić & Morske Orgulje & 2004 & 2005 & Zadar & Croacia & Adriático \\
\hline White Arkitekter & Kastrup Sea Bath & - & 2005 & Copenhague & Dinamarca & Norte-Báltico \\
\hline- & Badeschiff Wien & - & 2006 & Viena & Austria & Río \\
\hline Sequana Architecture & Piscine Joséphine Baker & - & 2006 & París & Francia & Río \\
\hline Bjørbekk \& Lindheim & Tjuvholmen Fjord Bath & 2003 & 2008 & Oslo & Noruega & Fiordo Oslo \\
\hline Snohetta & Opera House & 2000 & 2008 & Oslo & Noruega & Norte \\
\hline Jonathan Kirschenfeld & The floating Pool & 1999 & 2009 & Nueva York & EEUU & Cualquiera \\
\hline IOU Architecture & BadBuiten & 2010 & 2010 & Ámsterdam & Holanda & Río Amstel \\
\hline- & Sluseholmen harbour bath & - & 2011 & Copenhague & Dinamarca & Norte-Báltico \\
\hline Thorbjörn Andersson & Dania Park & 1999 & 2011 & Malmö & Suecia & Norte-Báltico \\
\hline Thorbjörn Andersson & Umeå Campus Park & - & 2011 & Umeå & Suecia & Lago \\
\hline $\mathrm{BIG}$ & Vinterbad Bryggen & - & 2012 & Copenhague & Dinamarca & Norte-Báltico \\
\hline Rintala Eggertsson & Floating SPA & 2011 & 2012 & Køge bay & Dinamarca & Lago \\
\hline JDS + KLAR Ar. & Kalvebod Waves & 2008 & 2013 & Copenhague & Dinamarca & Norte-Báltico \\
\hline Sculp IT & Badboot & 2012 & 2013 & Amberes & Bélgica & Río Escalda \\
\hline White Arkitekter & Hasle Harbour Bath & - & 2013 & Hasle & Dinamarca & Báltico \\
\hline Db Traebyg & badebro ved Jels Søbad & 2014 & 2014 & Copenhague & Dinamarca & Lago \\
\hline Gunter Henn & VW_Ritz-Carlton & 2000 & 2014 & Wolfsburgo & Alemania & Lago artificial \\
\hline JDS + Urban Ag. & Faaborg Harbour Bath & 2011 & 2014 & Faaborg & Dinamarca & Norte-Báltico \\
\hline RO\&AD Architecten & Pedestrian Bridge & - & 2014 & Bergen & P. Bajos & Lago \\
\hline- & Sjøbadet & - & 2015 & Myklebust & Noruega & Norte \\
\hline Bow-Wow & Swimmwer Club & - & 2015 & Brujas & Bélgica & Canal \\
\hline FORCE4arch. & Floating Kayak Club & - & 2015 & Vejle & Dinamarca & Norte-Báltico \\
\hline LPO & Sørenga Sjøbad & - & 2015 & Oslo & Noruega & Fiordo Oslo \\
\hline White Arkitekter & Karlshamns Kallbadhus & - & 2015 & Karlsham & Suecia & Báltico \\
\hline Avanto & Löyly & 2011 & 2016 & Hernesaari & Finlandia & Báltico \\
\hline goCstudio & Sauna Flotante & - & 2016 & Seattle & EEUU & Lago Union \\
\hline Niko Hoebe & Engelsmanplaant & - & 2016 & Holanda & P. Bajos & Norte \\
\hline VVAA & Allas Sea Pool & - & 2016 & Helsinki & Finlandia & Báltico \\
\hline- & The Bassin de la Villette & - & 2017 & París & Francia & C. de l'Ourcq \\
\hline ADEPT & Vestre Fjordpark & - & 2017 & Aalborg & Dinamarca & Norte-Báltico \\
\hline Bas Smets & Kalani Beach Resort & 2015 & 2017 & Halat & Líbano & Mediterráneo \\
\hline Bas Smets & Himara Waterfront & 2014 & 2017 & Himara & Albania & Jónic.-Adriát. \\
\hline Diller Scofidio & Zaryadye Park & 2013 & 2017 & Moscú & Rusia & Río Moscova \\
\hline Small Arch. Work. & Sauna on Sweden Lake & - & 2017 & Amot & Suecia & Lago \\
\hline $\mathrm{BIG}$ & Harbour Bath & - & 2018 & Aarhus & Dinamarca & Norte-Báltico \\
\hline
\end{tabular}

Fuente: elaboración propia

Como hemos comentado anteriormente, las referencias estudiadas configuran un atlas sintético que clasifica los proyectos según un mismo esquema que permite conocer sus aspectos más 


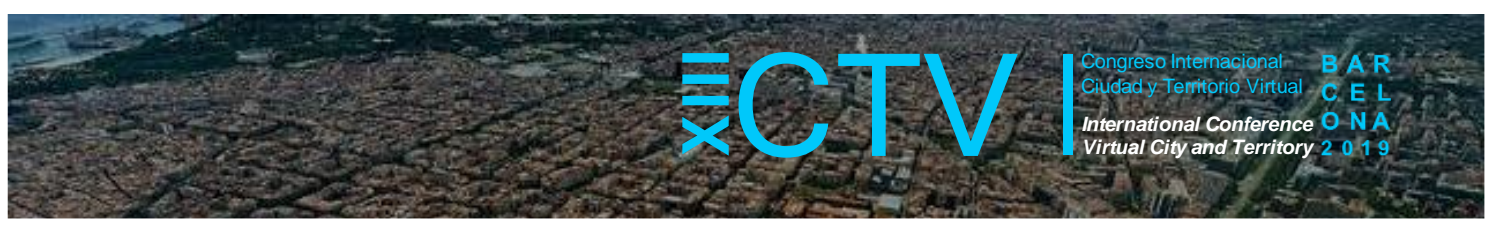

reveladores. En la Tabla 2 se amplía la documentación de la tabla anterior, añadiendo a cada caso de estudio una serie de categorías de análisis según sus componentes estratégicos. El atlas de casos y situaciones pretende desvelar distintas características fundamentales para entender las complejas y fluctuantes negociaciones establecidas por la arquitectura y el paisaje litoral. Las categorías analizadas son seis:

1. Estrategia de posicionamiento: se definen aquellos conceptos que regulan la posición de la intervención con respecto a la cota cero o de contacto entre costa y mar. Acciones definidas por un corte en sección del terreno.

2. Transformación en contacto: se enumeran distintos conceptos relativos a la transformación de la línea de costa en relación a la forma en la que se genera el contacto tierra-agua. Acciones definidas por la vista en planta de la propuesta.

3. Relación Espacio público-mar: se distinguen aquellos conceptos característicos que definen la propuesta en relación a su comportamiento como objeto con respecto al agua. Cualidades que definen al proyecto como un material en contacto con el medio líquido.

4. Recursos y energía: este apartado hace referencia a una doble vertiente que evalúa el aprovechamiento de la intervención de los recursos existentes en la línea de costa y la energía que opone la arquitectura a las variaciones producidas por el nivel del mar.

5. Usos y costumbres: se analiza la relación del espacio público respecto a valores patrimoniales intangibles, usos y costumbres del lugar en el que se lleva a cabo la propuesta. Es la vinculación del uso introducido por el proyecto respecto a los usos desarrollados en los emplazamientos con carácter previo a la construcción de la propuesta.

6. Valor simbólico: se estudian las características propias de la arquitectura definiendo los principales valores del espacio público y su simbología como intermediario entre la tierra y el mar.

Por tanto, consideramos las acciones que regulan los posicionamientos de las intervenciones respecto al nivel del mar, nos referimos a cómo la arquitectura reacciona frente al agua, es decir, al comportamiento del elemento construido frente al mar. Procedemos así a evaluar el aprovechamiento que cada una de las intervenciones analizadas realiza a partir de los recursos existentes en la línea de costa, considerando también la energía que la arquitectura opone a las variaciones del nivel del mar. Se estudia, finalmente, la relación del espacio público con ciertos valores patrimoniales tangibles e intangibles, los usos y costumbres del lugar en el que se inserta, analizando las principales características de la intervención desde el prisma del espacio público y su valor arquitectónico como intermediario entre la tierra y el mar.

Cada proyecto posee una estrategia determinada. Esta se define como la combinación de conceptos vinculados al paisaje litoral. La respuesta que las intervenciones dan al medio en el que se encuentran será el resultado de la aplicación de varios componentes estratégicos que dependerán de múltiples factores relativos a su contexto (Castellano y García, 2011).

Se sistematizan y extraen los principales componentes estratégicos de cada propuesta para agruparlas en tipologías específicas. Aun así, la mayoría de los proyectos son respuestas 


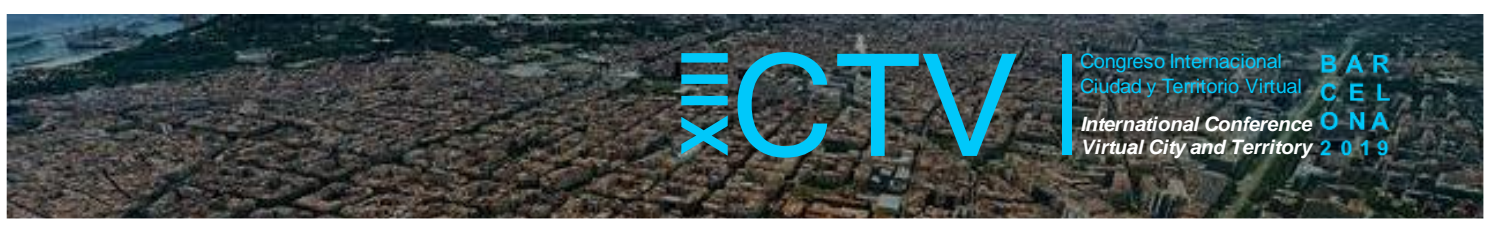

híbridas que negocian con una realidad compleja y fluctuante como es el paisaje litoral. Debido a este carácter híbrido de las arquitecturas litorales, es común encontrar proyectos que siguen múltiples componentes estratégicos generalmente adscritos a una estrategia principal. Los proyectos, pues, se definen a través de una serie de acciones que construyen un vocabulario propio que describe la interacción de la arquitectura con el paisaje litoral.

En la Tabla 2 las filas han sido coloreadas en cuatro tonos distintos, fruto del análisis pormenorizado y la clasificación de los proyectos en grupos que siguen estrategias similares. Esta clasificación nos sirve para agrupar los proyectos y extraer un caso de estudio representativo de cada uno de ellos para examinar las estrategias seguidas, sus potencialidades y aspectos a mejorar. Los colores definen colecciones de proyectos que responden a componentes estratégicos como los que se exponen a continuación:

- Grupo 1. Arquitecturas sobre-elevadas: son intervenciones que basan su estrategia de posicionamiento en la elevación sobre el agua. Sustentados en estructuras que apoyan en el terreno, definen un plano continuo sobre el mar que no se altera ante las variaciones de éste.

- Grupo 2. Arquitecturas flotantes: la principal característica de estos proyectos es la flotabilidad. El elemento arquitectónico se adapta a las variaciones del nivel del mar.

- Grupo 3. Arquitecturas intersticiales: son arquitecturas del baño construidas en el contacto entre la tierra y el mar. Piscinas, normalmente entre rocas, en donde la arquitectura se inserta introduciendo los mínimos elementos posibles para facilitar la contención de las aguas.

- Grupo 4. Arquitecturas graduales: son arquitecturas posadas en la tierra y que conducen al mar. Intervenciones duras que generan espacios públicos vinculados al baño, capaces de negociar las variaciones del nivel del agua de forma muy diversa.

Figura 1. De izqda. a drcha.: Kastrup Sea Bath (sobre-elevada), Copenhagen Harbour Baths (flotante), Piscinas de Leça de Palmeira (intersticial) y Himara Waterfront (gradual)

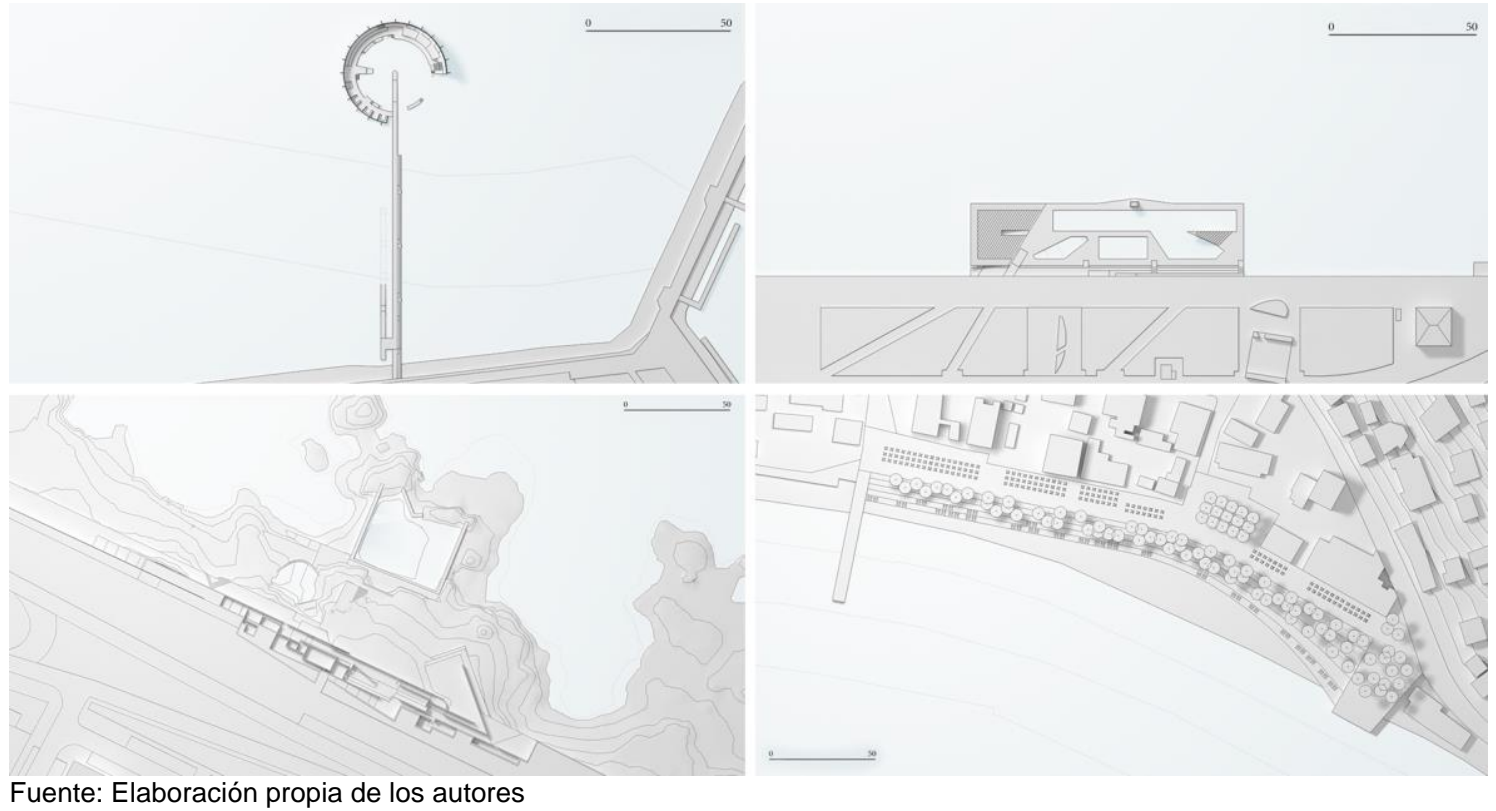


Tabla 2. Casos de estudio. Atlas de referencias arquitectónicas

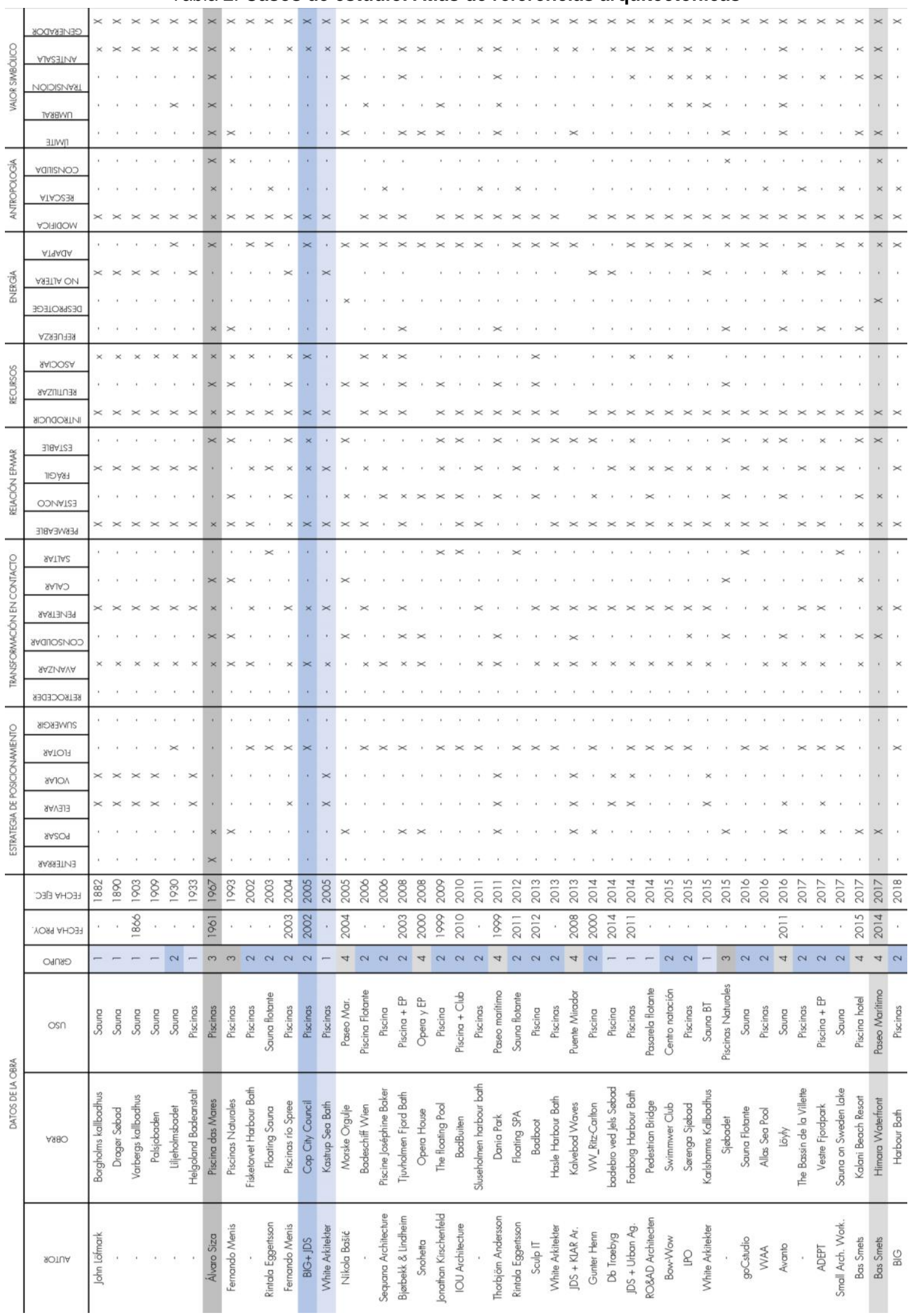

Fuente: Elaboración propia de los autores 


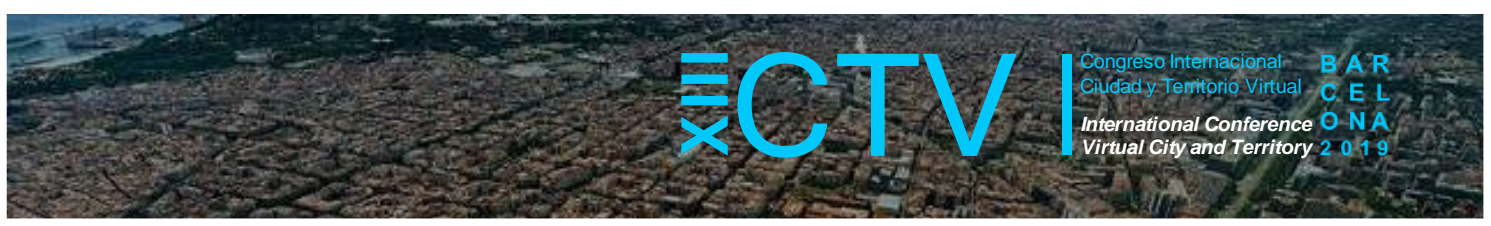

\subsection{Arquitecturas sobre-elevadas. El caso del Kastrup Sea Bath: White Arkitekter, Copenhague, $2004-2005$}

Un muelle de madera se eleva desde la línea de costa adentrándose en el mar y conduciendo a una plataforma circular que soporta la carga programática al mismo tiempo que rodea y acota la zona de baño. El proyecto establece un plano principal sobre la lámina de agua e introduce una serie de pasarelas contiguas con niveles que permiten adaptarse a las variaciones mareales.

Esta propuesta se basa en las arquitecturas sobre pilotes tradicionales de las casas de baño y las saunas nórdicas, rescata la costumbre vernácula del baño frío en mar abierto y se configura como un generador social público de ocio y esparcimiento.

La estructura sobre pilotes eleva la construcción para salvaguardarla de las mareas sin oponer resistencia ni alterarse ante la subida del nivel del mar.

Soporte estructural y celosía

La estructura sobre palafitos sirve para soportar las cargas de la plataforma principal, absorber las variaciones del nivel del mar y arriostra la celosía exterior de madera.

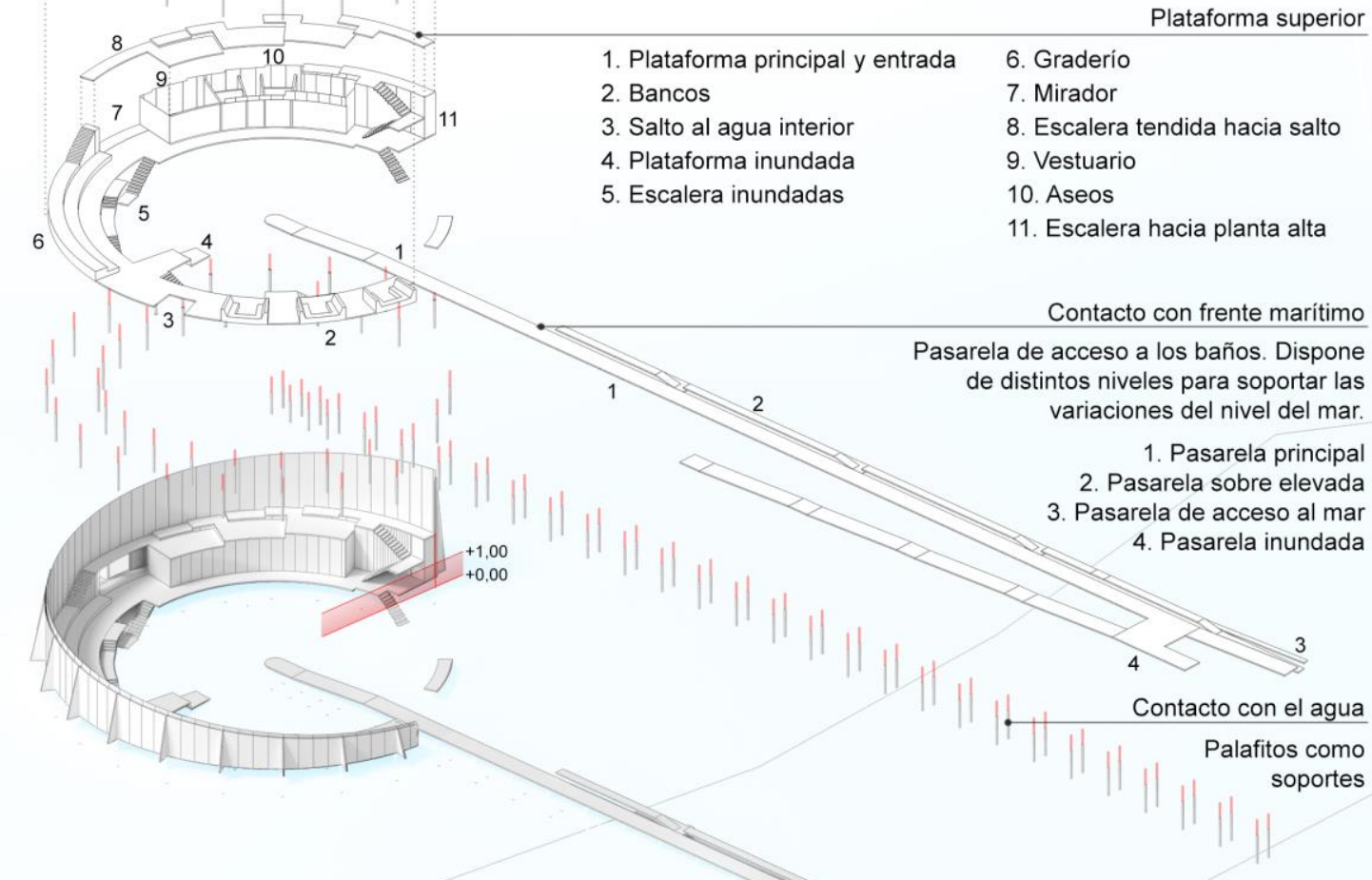

*Aunque son elementos fijos, soportarian posibles ampliaciones en altura.

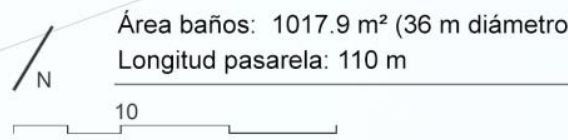




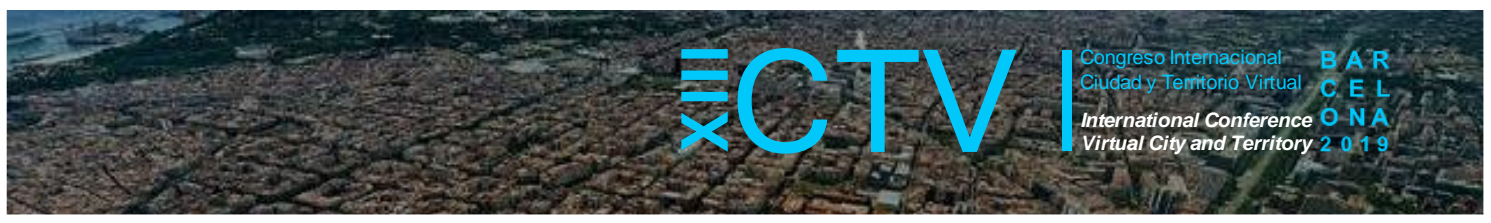

\subsection{Arquitecturas flotantes. El caso del Copenhagen Harbour Baths, BIG + JDS, Copenhague, 2005 - 2012}

Los baños del puerto de Copenhague forman parte del plan de regeneración urbana propuesto tras la pérdida de carga del espacio portuario de la capital danesa. Frente a los tradicionales baños nórdicos sobre pilotes, se propone un dispositivo arquitectónico que toma componentes estratégicos de los muelles secos, embarcaderos y pontones estableciendo una relación de flotabilidad con el mar.

La arquitectura avanza hacia el agua adaptándose a ella y vinculándose al frente costero mediante una pieza escalonada que está preparada para absorber las variaciones producidas por las mareas.

Tras la primera propuesta, finalizada en 2005, en 2012 se decidió ampliar la zona de piscinas con una pieza cubierta de sauna y baño caliente (en rojo). De esta manera, el lugar pasó a tener un funcionamiento y un uso intenso durante todas las estaciones del año.

\section{Contacto con frente marítimo}

Admite las variaciones del nivel del mar.

Posee distintos niveles, rampas, escalones y graderío.

Plataforma superior

1. Propuesta del año 2004 , creación de piscinas. Estudio JDS + BIG.

2. Ampliación año 2012, creación de sauna, baños para invierno y graderio de verano. Estudio BIG.

Contacto con el agua: Estructura flotante, pontones

Admite las variaciones de altura producidas por el nivel del mar adaptándose a ellas.

1. Plataforma principal

2. Piscina para bebés

3. Piscina para niños

4. Piscina para adultos

5. Graderio y salto hacia el agua

6. Torre de vigilancia

7. Pieza de conexión con puerto y acceso

8. Ampliación año 2012. Baños de invierno

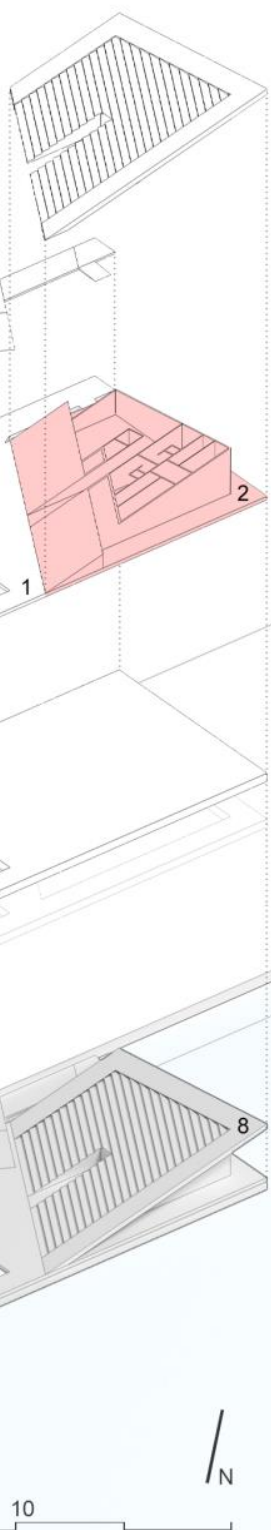

Superficie: 2075 m

Longitud lado mayor: $94 \mathrm{~m}$. 


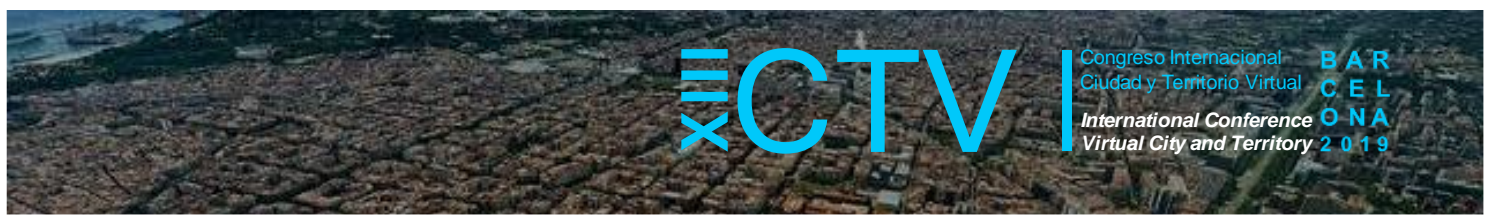

\subsection{Arquitecturas intersticiales. El caso de las Piscinas de Leça de Palmeira, Álvaro} Siza, Matosinhos, 1961-1967

Las piscinas de Leça de Palmeira se sitúan en una agrupación de rocas en donde ocasionalmente se conformaban pequeños lagos que eran utilizados por los lugareños para tomar baños a salvo de las fuertes corrientes marinas del océano atlántico. Las rocas son aprovechadas para crear las piscinas ayudándose de la introducción de los mínimos muros posibles que potencian la relación entre naturaleza y elemento construido.

El acceso y la dotación de instalaciones se apoyan en el muro de contención que limita con la playa, generando una secuencia longitudinal de espacios previos al mar.

Se trata de una intervención compleja que reúne varios componentes estratégicos. La arquitectura presta especial atención y cuidado por el medio en el que se inserta configurándose como umbral, límite y transición entre la ciudad y el mar. Los muros consolidan las piscinas oponiendo resistencia a las mareas a la vez que permiten el intercambio de agua.

\section{Contacto con frente maritimo}

El edificio se inserta en el antiguo paseo marítimo,

funcionando como umbral entre ciudad y el mar.

Secuencia de horizontales

Mar, playa, cubiertas y paseo maritimo configuran una secuencia de horizontales

Programa

1. Piscinas adultos y niños

2. Plataformas entre rocas

3. Rampa y control acceso

4. Vestuarios

5. Aseos y baños

6. Cuartos de

instalaciones

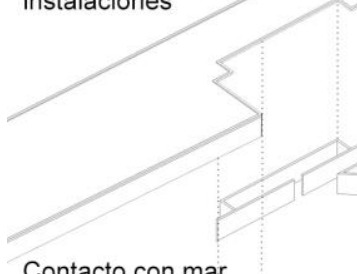

Las rocas y los muros en sus intersticios contienen el agua de las piscinas.

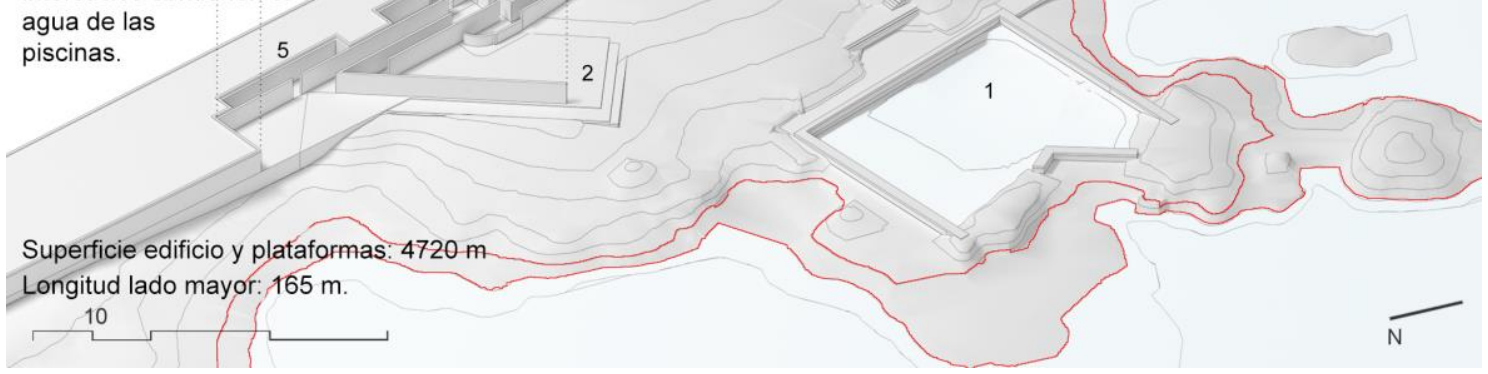




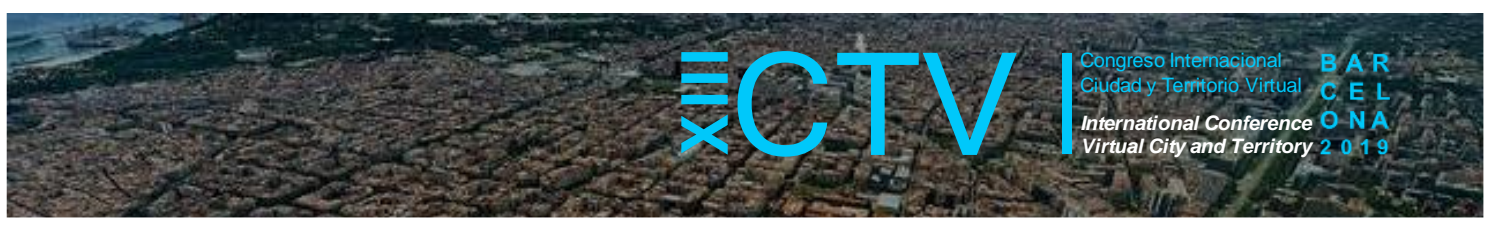

\subsection{Arquitecturas graduales. El caso del Himara Waterfront, Bureau bas Smets, Himara, $2014-2017$}

El frente marítimo de Himara, en Albania, disponía de un muro de contención elevado que interrumpía la conexión entre la ciudad y la playa. El proyecto elimina resistencia al agua posando una serie de plataformas aterrazadas que suavizan la transición al mar. Estas plataformas tendidas absorben el impacto de las olas adaptándose a las variaciones del nivel del mar.

La nueva conexión que se establece permite remodelar la fachada de la ciudad hacia el mar, crea lugares estanciales en sombra mediante la introducción de un frente arbolado y ha posibilitado la aparición de nuevas actividades públicas en los espacios recuperados tras la eliminación del frente duro anterior.

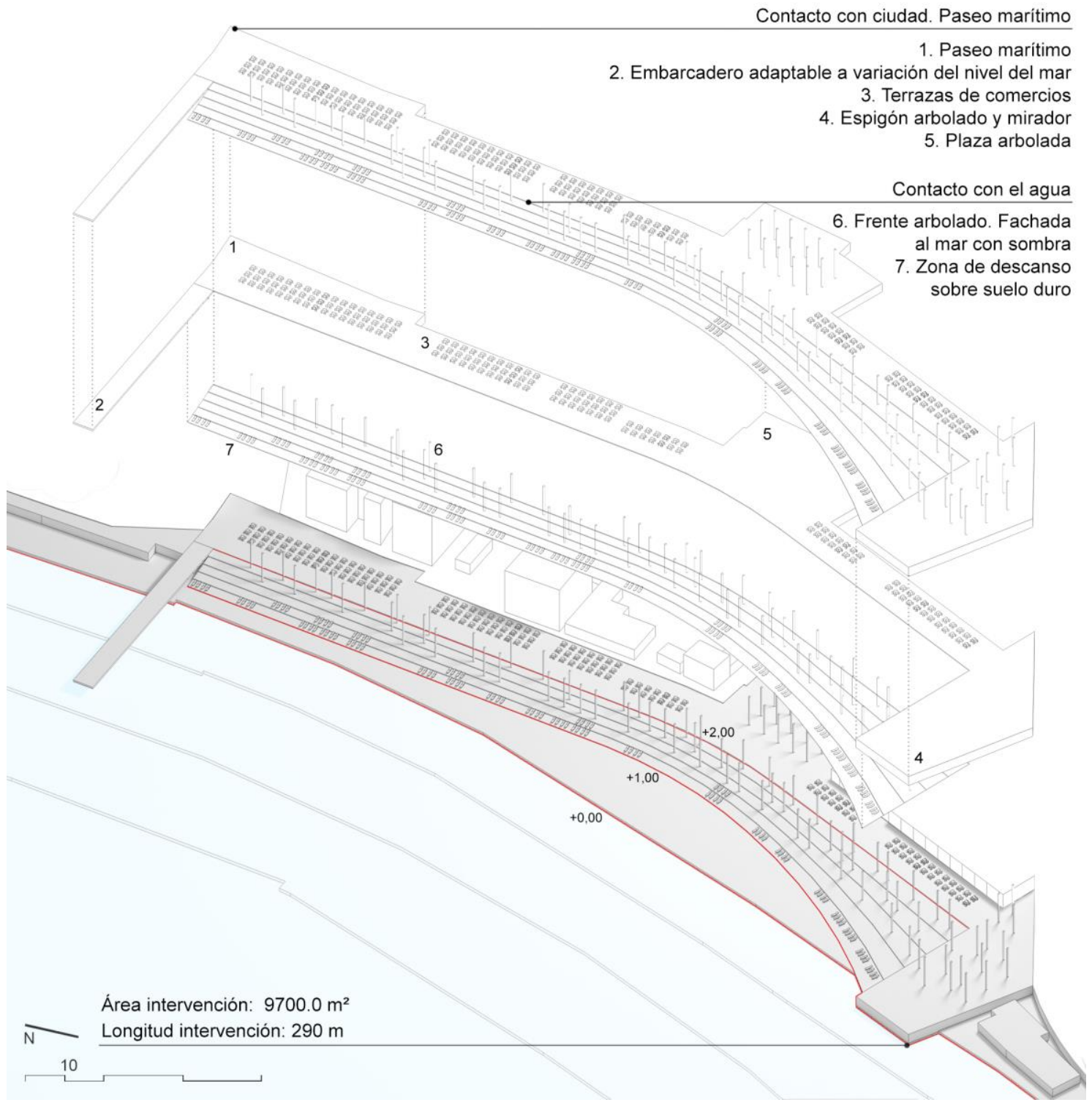




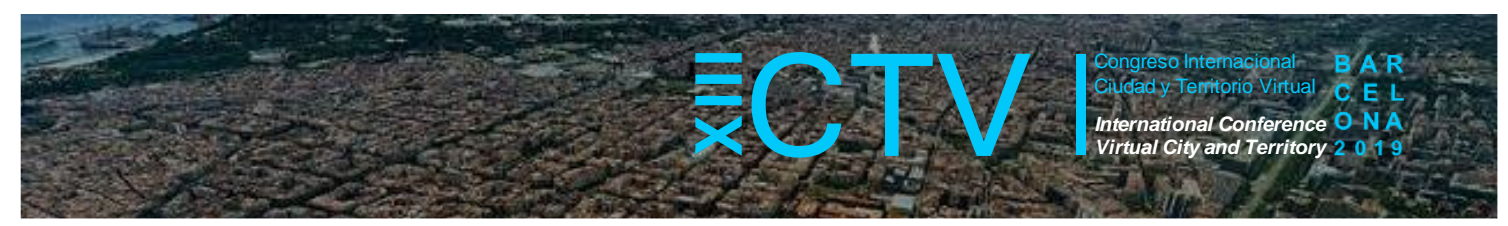

\section{Conclusiones}

Ante los cambios proyectados por el sistema climático urge trabajar con escenarios de anticipación que asuman marcos temporales mayores a los considerados en la actualidad. Se deben realizar estudios de anticipación que prevean riesgos futuros en los frentes marítimos para proyectar soluciones híbridas con capacidad de adaptación a nuevas necesidades.

La historia de las arquitecturas del baño se concibe como una respuesta evolutiva a la adaptación de las dinámicas marinas. El atlas de proyectos generado, fruto de la clasificación y estudio pormenorizado de las intervenciones arquitectónicas vinculadas al baño, permite sistematizar un método de análisis y generar una cartografía propia asociada a la investigación.

En este documento se analizan cuatro casos de estudio representativos que aglutinan características comunes a otra serie de proyectos. De este modo se plantea un análisis conceptual en donde el principal valor de las intervenciones reside en las conclusiones obtenidas a través de las estrategias seguidas en cada caso:

Arquitecturas sobre-elevadas. Las arquitecturas que se elevan e introducen sobre el mar son la solución más profusamente utilizada a lo largo de la historia. Los pilotes sobre los que se alzan permiten salvar los envites de las olas si bien la longitud de estos elementos verticales puede limitar su respuesta. Un aumento del nivel del mar mayor de lo previsto puede solucionarse permitiendo la ampliación en altura de los elementos de sustentación.

Arquitecturas flotantes. Las construcciones flotantes son las que mejor pueden adaptarse a los cambios producidos por las variaciones del nivel del mar. Además, son arquitecturas preparadas para poder desplazarse a otras ubicaciones distintas a las pensadas en origen, pueden modularse para poder crecer o decrecer según las necesidades programáticas y tienen grandes ventajas en el uso de energías renovables al estar ubicadas en vastos territorios.

Arquitecturas intersticiales. Las construcciones intersticiales analizadas basan su implantación en el territorio a través cuidadoso respeto por el medio en el que se introducen. Estas arquitecturas fundamentan su éxito para salvar las subidas del nivel del mar en el conocimiento de las dinámicas marinas y deben tener en cuenta las proyecciones a largo plazo. De lo contrario, pueden ser absorbidas por el agua desapareciendo bajo el mar.

Las arquitecturas graduales. Estas intervenciones funcionan como transición entre ciudad y la costa por lo que configuran la fachada urbana hacia el mar. Mediante la introducción de graderíos y superficies aterrazadas se consigue tender un camino al mar absorbiendo la fuerza de las olas a la vez que se elimina el componente amurallado de los diques y frentes duros de contención. Requieren un conocimiento profundo de la evolución del nivel del mar.

- Los resultados extraídos del análisis y la catalogación de las arquitecturas del baño son utilizados para generar una colección de propuestas metodológicas de planeamiento y proyecto a diferentes escalas. Estas propuestas definen estrategias arquitectónicas extrapolables que pueden ayudar a la reinvención del frente marítimo ante los nuevos paradigmas costeros previstos por el cambio climático y la consiguiente subida del nivel del mar. 


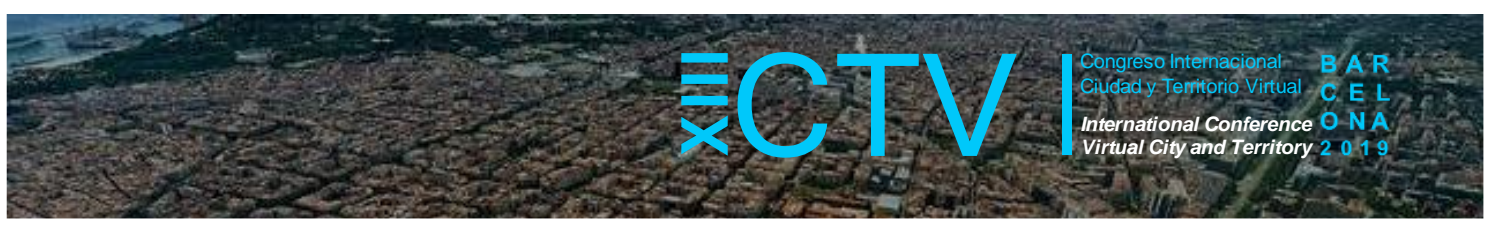

Conflicto de Intereses: No hay conflicto de intereses entre los autores.

\section{Bibliografía}

Bamber, J. L., et al. (2009). Reassessment of the Potential Sea-Level Rise from a Collapse of the West Antarctic Ice Sheet. Science, 324 (5929), 901-03.

Cabral Matos, M. (2016). Public space design for flooding: facing the challenges presented by climate change adaptation (Tesis doctoral). Facultat de Belles Arts, Barcelona.

Castellano Pulido, F. J., García Píriz, T. (2011). Arquitectura Predictiva para El Litoral Andaluz. Análisis, diagnóstico y propuestas sobre la evolución de la ribera del mar. Consejería de Obras Públicas. Recuperado de https://www.juntadeandalucia.es/.html

Fernández Fúster, L. (1991). Historia General del Turismo de Masas. Madrid, España: Alianza Editorial.

Gonzáles Soutelo, S. (2008). Los baños de agua de mar en el mundo antiguo: una propuesta de estudio. Gallaecia, no27, 227-240.

Hinkel, J. et al. (2018). The Ability of Societies to Adapt to Twenty-First-Century Sea-Level Rise. Nature Climate Change, 8 (7), 570-78.

Iguarán, J. (1972). Historia de la Natación antigua y de la moderna de los juegos olímpicos. Madrid, España: Gráfica Valverde.

Llana Belloch, S., Pérez Soriano, P., Aparicio Aparicio, I., (2011). Historia de la natación I: desde la prehistoria hasta la edad media. Citius, Altius, Fortius, 4 (2)-2011, 51-83.

Losada M.A., Baquerizo, A., Ortega-Sánchez, M. y Ávila, A. (2011). Coastal evolution, sea level and assessment of intrinsic uncertainty. Journal of Coastal Research, SI 59, 218-228.

Martínez, A. (2008). Un palacio sobre raíles para el baño real. Fogonazos. Asombros diarios. Recuperado de http://www.fogonazos.es/2008/10/un-palacio-sobre-rales-para-el-bao-real.html

Masters, N. (2013). Swimming Pools at the Beach? When L.A. Took the Plunge. KCET. Recuperado de https://www.kcet.org/shows/lost-la/swimming-pools-at-the-beach-when-la-tookthe-plunge

Morrison, J. (2018). Flooding Hot Spots: Why Seas Are Rising Faster on the U.S. East Coast. Yale Environment360. 24 de abril del 2018. Recuperado de: https://e360.yale.edu/

Moon, C. (2017). Architectural Characteristics of Floating Building. Trabajo presentado en: UIA 2017 Seoul Architects Congress, Seúl, Corea del Sur. Resumen recuperado de http:// http://www.uia2017seoul.org

Pardo Díaz, G., (2016). Cuerpo y Casa. Hacia el espacio doméstico contemporáneo desde las transformaciones de la cocina y el cuarto de baño en occidente. (Tesis doctoral). E.T.S.A. de Madrid.

Schiermeier, Q. (2011). Increased flood risk linked to global warming. Nature, 470, 378-381. 


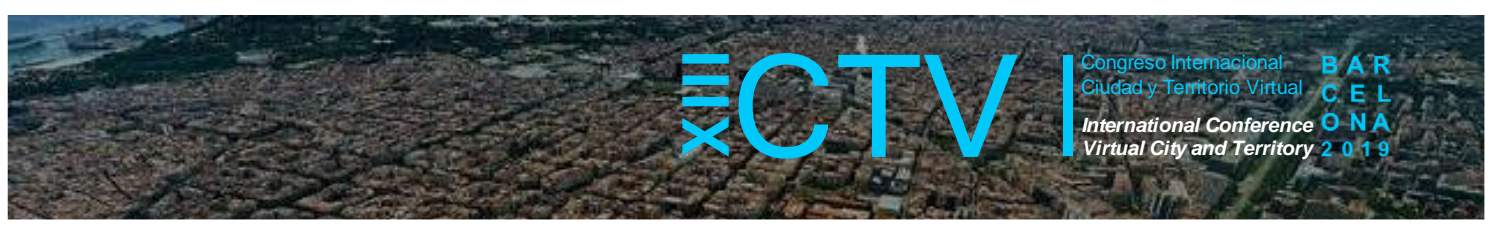

Strauss, B. (2015). Coastal Nations, Megacities Face 20 Feet of Sea Rise. Climate Central. 9 de Julio del 2015.

Szoenyi, M. (2018). Flood Resilience Alliance 2.0: A Look at Five Years of Supporting Communities Building Resilience against Floods. Zurich Insurance Company. 3 de Julio del 2018.

The World Bank. (2010). Cities and Climate Change: An Urgent Agenda. Diciembre del 2010, Vol. 10. Washington. Recuperado de: https://siteresources.worldbank.org/

VVAA. (2010). Copenhagen City of Architecture. Technical and Environmental Administration

VVAA. (2019). (FEM) Informe de riesgos mundiales 2019, 14a edición. Luchar o huir. Preparación para la subida del nivel del mar. Foro Económico Mundial. Ginebra, Suiza.

Yegül, F. (1991). Bath and bathing in Classical Antiquity. Nueva York, EEUU. 